\title{
Lateral Stiffiness of Masonry Infilled Reinforced Concrete (RC) Frames with Central Opening
}

\author{
Goutam Mondal ${ }^{\text {a) }}$ and Sudhir K. Jain, M.EERI
}

\begin{abstract}
Window and door openings are inevitable parts of infill walls for functional reasons. Currently, publications like FEMA-273 and ATC-40 contain provisions for the calculation of stiffness of solid infilled frames mainly by modeling infill as a "diagonal strut." However, such provisions are not provided for infilled frames with openings. The present study proposes a reduction factor for effective width of diagonal strut over that of the solid reinforced concrete (RC) infilled frame to calculate its initial lateral stiffness when a central window opening is present. The study is based on initial lateral stiffness which is taken at $10 \%$ of the lateral strength of the infilled frames.
\end{abstract}

[DOI: 10.1193/1.2942376]

\section{INTRODUCTION}

Performance of buildings in the recent earthquakes (e.g., 1985 Mexico City earthquake, 2001 Bhuj earthquake) clearly illustrates that the presence of infill walls has significant structural implications. Therefore, the structural contribution of infill walls cannot simply be neglected particularly in regions of moderate and high seismicity where, the frame-infill interaction may cause substantial increase in both stiffness and strength of the frame in spite of the presence of openings. Generally, presence of these openings decreases stiffness and strength of infilled frames. A review of analysis and design provisions related to masonry infilled $\mathrm{RC}$ frames in seismic design codes of different countries shows that only a few codes have considered the effect of infill in analysis and design of masonry infilled RC frames (Kaushik et al. 2006). On the other hand, the stiffness and strength of the infilled frames with opening are not taken care of by most of the codes. Hence, the behavior of infilled frames with openings needs to be studied extensively in order to develop a rational approach or guidelines for design.

In the present study, a finite element (FE) analysis has been carried out on single-bay single-story, single-bay two-story, and single-bay three-story infilled frames to examine the effect of central openings of different sizes on the initial lateral stiffness of infilled frames. Lateral load-deflection curve of an infilled frame can be divided into three parts. In the initial part, there may be a lack of fit between frame and infill. The second part is approximately linear and reflects the interaction between frame and infill. In the present study, this stiffness has been considered assuming that this is achieved well before a load level of $10 \%$ of the lateral strength of infilled frame. In the third part of lateral loaddeflection relationship, a stiffness reduction may take place due to progressive degrada-

\footnotetext{
a) Department of Civil Engineering, Indian Institute of Technology Kanpur, India 208016
} 
tion of the infill material with increasing stress. A substantial variation of stiffness has been observed in this part due to variation of material properties and failure mechanism. Because the aim of the present paper is to study the effect of opening on stiffness (rather than the value of stiffness as such), the stiffness degrading stage of the load-deflection curve is not considered. Therefore, the initial lateral stiffness is defined as the stiffness at lateral load level corresponding to $10 \%$ of the lateral strength of infilled frame. The FE model has been verified using experimental results of seven different specimens published in the literature. Based on the parametric study, a reduction factor is proposed to determine the width of strut for a central opening present in an infilled frame.

The stiffness of infilled frames is influenced by the size and location of the openings. Experiments on four story steel frames with RC infills illustrated that a central opening of size $20 \%-30 \%$ of the panel area may reduce the stiffness by about $70 \%-80 \%$ in absence of shear connector (Liauw 1979). Based on experimental and analytical research, it was found that an opening at either end of the loaded diagonal reduces the stiffness of infilled frame by about $85 \%-90 \%$ in comparison with infilled frame without opening (Mallick and Garg 1971). Usually, a RC band/stiffener around the opening increases the stiffness of the infilled frame. Effects of different types of RC bands/stiffeners on the stiffness of infilled frame were studied by Polyakov (1956), Dawe and Seah (1989), Jagadish et al. (1992), and Raj (2000).

Analytical models that have been developed to estimate lateral stiffness and strength of the infilled frames with openings include the equivalent frame model, the single diagonal strut model, and the multi-diagonal strut model. The equivalent frame model is based on the concept of equivalent frame, where members have the properties of the composite sections of the actual structure (Liauw 1972, Kodur et al. 1998). The equivalent diagonal strut model is the most simplified yet reasonably accurate macro-model. This is usually done by modeling the infill panel as a single diagonal strut connected to the two compressive diagonal corners. The key to this approach lies in determination of effective width of equivalent diagonal strut. In the last few decades, several attempts have been made to compute the effective width of diagonal strut for infilled frames without opening (Holmes 1961, Smith and Carter 1969, Mainstone 1971, Liauw and Kwan 1984, Paulay and Priestley 1992). The effective width of diagonal strut for infilled frame without opening may be reduced by a reduction factor to simulate the presence of openings of various aspect ratios in the infilled frame (Durrani and Luo 1994, Al-Chaar 2002). Multi-strut models were proposed to represent the local effects due to presence of an opening (Thiruvengadam 1985, Buonopane and White 1999, Al-Chaar 2002).

The published researches on infilled frames point to a need for suitable quantitative design provisions to account for effect of openings. The expression for strut-width proposed by Durrani and Luo (1994) can be used to obtain the lateral stiffness of infilled frames due to presence of central opening. It was developed numerically on the basis of Finite Element (FE) analyses only and was not verified with experimental results. The expression developed by Durrani and Luo are somewhat too complex for use in design office because these account for beam stiffness, column stiffness, and both infill and panel aspect ratios. On the other hand, strut-width proposed by Al-Chaar (2002) is simpler than that proposed by Durrani and Luo (1994). It is based on both experimental and 


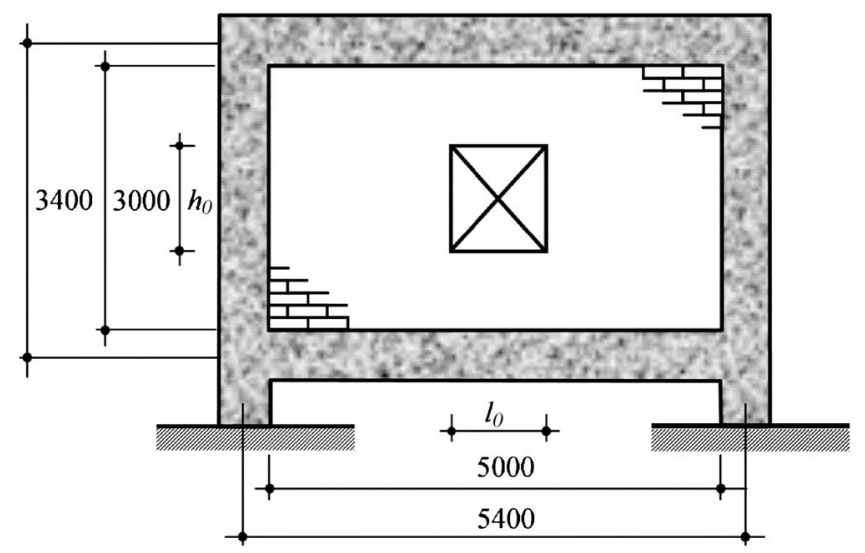

Figure 1. Dimensions $(\mathrm{mm})$ of single-bay, single-story infilled frame with symmetric central opening (infill thickness: $225 \mathrm{~mm}$; beam size: $250 \mathrm{~mm} \times 400 \mathrm{~mm}$; column size: $400 \mathrm{~mm}$ $\times 400 \mathrm{~mm}$ ).

numerical research. Pushover analysis of infilled frame with openings using Al-Chaar's width of strut predicts in-plane strength but underestimates the initial lateral stiffness. However, modification factors have been proposed by Al-Chaar to obtain a reasonable value of initial stiffness directly from the pushover curve. In the present paper a simple expression has been developed to obtain directly the initial lateral stiffness of infilled frames with a central opening. It is based on numerical study that has been calibrated and verified with published experimental results.

\section{METHODOLOGY}

A parametric study is performed to obtain lateral stiffness of infilled frames with varying sizes of central openings. In the study, two types of analysis methods are used: the FE method and the Single Equivalent Diagonal Strut (SEDS) method. The FE model is first calibrated using published results of experimental specimens available in the literature. This calibrated model is used in the parametric study to determine the lateral stiffness of infilled frames with openings. The width of equivalent diagonal strut for the SEDS method is estimated so as to obtain the same lateral stiffness as estimated from the FE method. That is, equivalent width of diagonal strut is determined that will give correct value of lateral stiffness. Finally, a strut-width reduction factor is proposed to multiply the "strut-width for fully infilled panel" proposed by some researchers earlier (e.g., Paulay and Priestley 1992, Liauw and Kwan 1984 and Holmes 1961).

In the parametric study, two parameters, i.e., number of stories and size of openings are considered. For this purpose, three sets of RC infilled frames, namely single-bay single-story, single-bay two-story, and single-bay three-story are analyzed and their lateral stiffness is determined by linear elastic analysis. The single-bay single-story infilled frame considered is shown in Figure 1. All the stories of two-story and three-story in- 


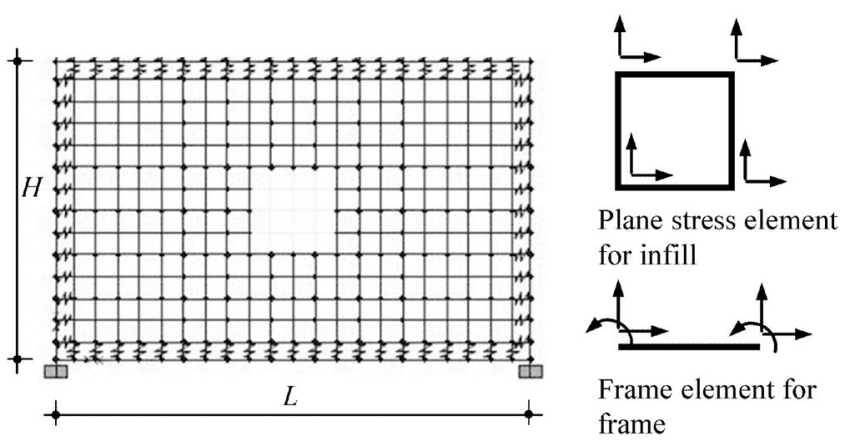

Figure 2. FE modeling of single-bay, single-story infilled frame with opening.

filled frames are identical to the single-bay single-story infilled frame. Central openings of widths $500 \mathrm{~mm}, 1000 \mathrm{~mm}, 1500 \mathrm{~mm}, 2000 \mathrm{~mm}, 2500 \mathrm{~mm}$ and $3000 \mathrm{~mm}$ are taken one at a time for each of these three sets of infilled frames. For each of these widths of opening, the considered heights of openings are $500 \mathrm{~mm}, 1000 \mathrm{~mm}, 1500 \mathrm{~mm}$, $2000 \mathrm{~mm}$ and $3000 \mathrm{~mm}$. Furthermore, one bare frame and one fully infilled frame of each of these three sets of infilled frames are analyzed. Thus a total of 96 models are analyzed in the parametric study. All the analyses are performed using the software SAP 2000 Version 8 (CSI 2000a, 2000b).

Masonry of compressive prism strength $5 \mathrm{MPa}$ and concrete having a characteristic compressive strength $\left(f_{c k}\right)$ of $25 \mathrm{MPa}$ are used. The characteristic compressive strength of concrete is specified by compressive strength of $150 \mathrm{~mm}$ size cube at 28 days (expressed in $\mathrm{MPa}$ ) which is almost 1.25 times the 28 day compressive strength of concrete cylinder specified in ACI 318-05 (2005). Poisson's ratios of masonry and concrete are taken as 0.18 and 0.20 , respectively. All the models are analyzed by applying lateral load in combination with gravity load. Lateral loads are taken as $10 \%$ of the lateral strength of the frames (Choubey and Sinha 1994) and are applied at the floor level as in the experimental models. Lateral strength of frames is estimated by the pushover analysis by using the modified diagonal strut model (Al-Chaar 2002).

\section{FINITE ELEMENT (FE) ANALYSIS}

In the FE method, standard two-noded frame elements with two translational degrees of freedom and one rotational degree of freedom at each node are used to model the frame elements. The infills are idealized by four-noded plane stress rectangular or square area elements with two translational degrees of freedom at each node (Figure 2). Interface of the infill and frame are modelled using linear springs incapable of taking any tension. Similar elements were also used earlier by some investigators, e.g., Thiruvengadam (1985). 
Table 1. Comparison of finite element analysis and experimental values for initial lateral stiffness ${ }^{\mathrm{a}}$

\begin{tabular}{|c|c|c|c|c|c|}
\hline \multirow[b]{2}{*}{ Model No. } & \multirow[b]{2}{*}{ Authors } & \multirow[b]{2}{*}{ Type of Specimen } & \multicolumn{2}{|c|}{ Stiffness $(\mathrm{kN} / \mathrm{mm})$} & \multirow{2}{*}{$\begin{array}{c}\text { Error } \\
(\%)\end{array}$} \\
\hline & & & FEA & Experimental & \\
\hline 1 & Choubey and Sinha (1994) & 1-Story 1-Bay Bare Frame & 3.8 & 3.9 & -2.4 \\
\hline 2 & Pillai (1995) & 5-Story 1-Bay Bare Frame & 3.9 & 4.4 & -20.7 \\
\hline 3 & Choubey and Sinha (1994) & $\begin{array}{l}\text { 1-Story 1-Bay Infilled Frame } \\
\text { without Opening }\end{array}$ & 37.9 & 25.4 & 49.3 \\
\hline 4 & Al-Chaar et al. (2002) & $\begin{array}{l}\text { 1-Story 1-Bay Infilled Frame } \\
\text { without Opening }\end{array}$ & 66.9 & 71.8 & -6.8 \\
\hline 5 & Pillai (1995) & $\begin{array}{l}\text { 5-Story 1-Bay Infilled Frame } \\
\text { without Opening }\end{array}$ & 12.5 & 29.3 & -57.6 \\
\hline 6 & Choubey and Sinha (1994) & $\begin{array}{c}\text { 1-Story 1-Bay Infilled Frame } \\
\text { with Opening }\end{array}$ & 14.6 & 16.0 & -8.8 \\
\hline 7 & Raj (2000) & $\begin{array}{c}\text { 1-Story 1-Bay Infilled Frame } \\
\text { with Opening }\end{array}$ & 25.6 & 25.5 & 0.4 \\
\hline
\end{tabular}

${ }^{\mathrm{a}}$ Semirigid end-offset, cracked flexural rigidity of components, $E_{m}=550 f_{m}$, and frame-infill separation are considered.

\section{CALIBRATION OF THE FE MODEL}

Experimental results available in the published literature for two RC bare frames, three RC infilled frames without any opening, and two RC infilled frames with central window openings are used to calibrate the FE model (Table 1). The influence of the following four factors namely, $(a)$ flexural rigidity of components $(b)$ modulus of elasticity of masonry, $(c)$ rigidity of beam-column junction, and $(d)$ the separation between frame and infill are examined in the FE analysis. Results of initial lateral stiffness by FE model are compared with experimental initial lateral stiffness and based on these comparisons a FE model is chosen for the subsequent parametric study. Cracking in infill and frame is not considered since the stiffness has been considered at a load level corresponding to $10 \%$ of the lateral strength of infilled frame. Since the present study focuses on the effect of opening on initial lateral stiffness of infilled frame, failure mode and material properties are not important parameters. Therefore, these parameters are not considered in the present study.

\section{Flexural Rigidity of Components}

In flexure dominated components (e.g., beams, columns, etc.), effective cross section of the member is reduced significantly due to the appearance of flexure cracks. Therefore, in the present study, two types of flexural rigidity of components are taken, namely flexural rigidity of components considering uncracked section and cracked section. Uncracked flexural rigidity of components is taken as $E_{c} I_{g}$, where $I_{g}$ is the gross cross section of the components and $E_{c}$ is the modulus of elasticity of concrete as per IS 456: 2000: 

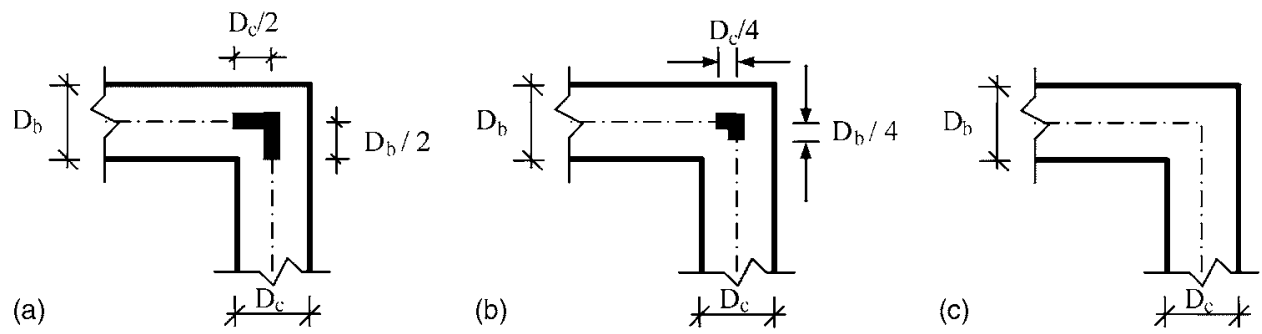

Figure 3. Modelling of beam-column joint-end-offsets: (a) rigid end-offset, (b) semirigid endoffset, and (c) flexible end-offset.

$$
E_{c}=5000 \sqrt{f_{c k}},
$$

where $f_{c k}$ is the characteristic compressive strength (MPa) of concrete cube at 28 days. Cracked flexural rigidity of components is taken as $0.5 E_{c} I_{g}$ in beam and in tension column and $0.7 E_{c} I_{g}$ in compression column, where $E_{c}$ is the modulus of elasticity (Equation 1) (ATC-40 1996, and FEMA-273 1997). For the specimens 2 and 5, the modulus of elasticity of concrete has been reported based on compressive tests on concrete cubes; these are used in separate cases.

\section{Modulus of Elasticity of Masonry}

Drysdale et al. (1993) have recommended that modulus of elasticity of masonry may be taken as:

$$
E_{m}=k f_{m},
$$

where $f_{m}$ is the compressive strength of masonry prism in MPa and $k$ lies between 500 to 600. In the present study, this expression is used with $k$ taken as 550 to model the initial stiffness of the infilled frames with openings.

\section{Rigidity of Beam-Column Junction}

In RC structures, the assumption of centerline dimensions is often inaccurate. Finite size of the joint can be modelled through the use of rigid-end-offsets option. In fact, rigid-end-offsets allow modeling the ends of a member such that these are not considered to be part of the flexible portion. In the present study, three types of rigidity of the beam-column joints namely, rigid, semirigid, and flexible are used to investigate the effect of finite size of the joint (Figure 3). In case of rigid beam-column joint, the endoffset is up to half column depth along beam from center line of column and half beam depth along column from center line of beam. In case of semirigid beam-column joint, rigid end-offset is upto quarter column depth along beam from center line of column and quarter beam depth along column from center line of beam while, in case of flexible beam-column joint, length of rigid end-offset is taken as zero. 


\section{Frame and Infill Interface}

In the present study, two types of frame-infill interface are considered. In the first type, separation between frame and infill is not allowed while in the second type, separation between frame and infill at the non-loaded diagonal is allowed. To account for this, linear springs are used as interface elements. Stiffness of the spring is the axial stiffness of mortar, i.e., $A_{m o r} E_{m o r} / t_{m}$ where, $A_{m o r}$ is the effective area of mortar, $t_{m}$ is the thickness of mortar, and $E_{m o r}$ is the modulus of elasticity of mortar. In absence of specific data on modulus of elasticity of the mortar, it is taken same as modulus of elasticity of masonry (i.e., $E_{m}=550 f_{m}$ ). As the mortar is weak in tension, its tensile strength is neglected in the FE analysis. For a given lateral load, the forces in these link elements are evaluated and those carrying tension are removed. The process is repeated till all the links remaining are in compression and the contact lengths are established. Due to unavailability of reliable data on stiffness of mortar it was assumed that the axial stiffness of mortar and brick is comparable. Hence, after identifying the length of contact, the link elements are done away with and the infill is extended to the centerline of the frame at the contact portion and the frames are analyzed to obtain the lateral stiffness. This slightly increases the overall stiffness of infilled frames.

\section{Results}

Results of the bare frames, i.e., specimen 1 and 2 show that the uncracked flexural rigidity of components results in up to $120 \%$ error (average 70\%). Models with flexible beam-column joints show up to $50 \%$ error with an average of $26 \%$. On the other hand, the models involving the combination of cracked flexural rigidity of components and rigid and semirigid beam-column joints result in maximum $20 \%$ error with an average error of $10 \%$.

Analysis of infilled frames, i.e., specimen 3, 4 and 5 shows that the modulus of elasticity of masonry based on Drysdale et al.'s (1993) empirical formula (Equation 2) yields reasonable estimate of the initial lateral stiffness. Complete contact between the frame and the infill resulted in large error in initial lateral stiffness, as large as $300 \%$. Therefore, the separation between frame and infill at the non-loaded diagonal proved to be a significant factor. Use of these two parameters along with the cracked flexural rigidity of components and semirigid beam-column joint, as discussed above, give the best correlation with experimental values of lateral stiffness; difference being up to $57 \%$ (with an average of 38\%). Therefore, this combination is considered for analysis of infilled frames with openings.

Use of the above mentioned parameters on infilled frames with openings resulted in less than $10 \%$ error in initial stiffness as compared to the experimental initial lateral stiffness. Therefore, results of the models considering cracked flexural rigidity of components, semirigid beam-column joint, and separation between frame and infill at the non-loaded diagonal are summarized in Table 1. Detailed results of all the other models are available elsewhere (Mondal 2003).

Figure 4 shows bar diagram of difference between FE model and experimental value of initial lateral stiffness for specimen 3, 4, 5, 6 and 7. Specimen 1 and 2 are not in- 


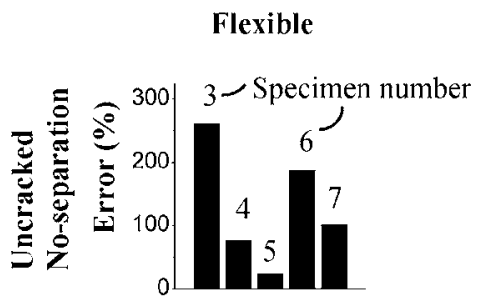

(a) UC_F_NS
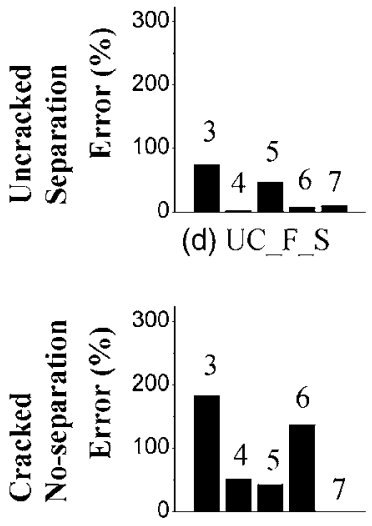

(g) C_F_NS

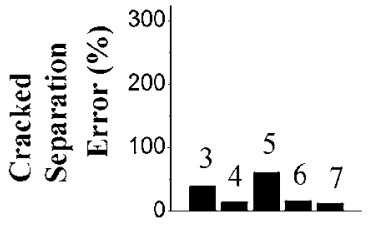

(j) $\mathrm{C}_{-} \mathrm{F}_{-} \mathrm{S}$

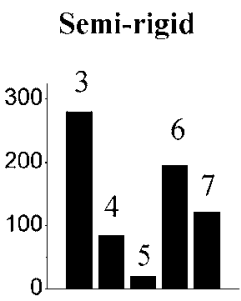

(b) UC_SR_NS

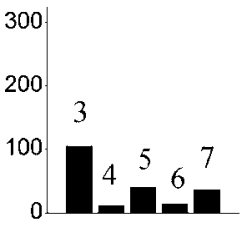

(e) UC_SR_S

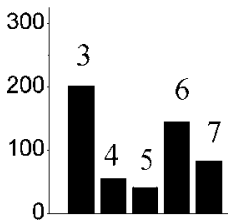

(h) C_SR_NS

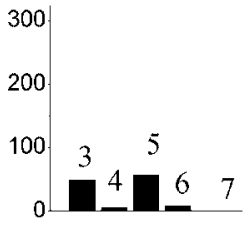

(k) C_SR_S

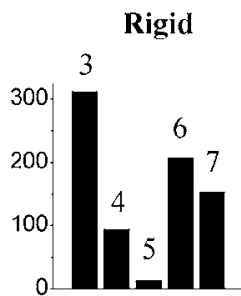

(c) UC_R_NS

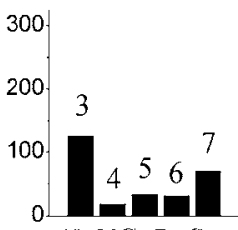

(f) UC R S

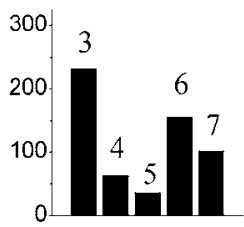

(i) C_R_NS

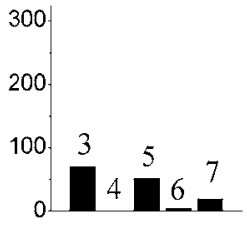

(I) C_R_S

Figure 4. Comparison of different FE models. (UC: uncracked flexural rigidity of components; C: cracked flexural rigidity of components; F: flexible end-offset; SR: semirigid end-offset; R: rigid end-offset; NS: no separation at the frame-infill interface; S: separation at the frame-infill interface).

cluded in the comparison since these are bare frames, where comparison of separation of frame and infill at non-loaded diagonal is meaningless. Comparisons of Figures $4 \mathrm{a}-4 \mathrm{c}$ with Figures $4 d-4 f$, and Figures $4 g-4 i$ with Figures $4 j-41$ show that separation of frameinfill interface at the non-loaded diagonal should be considered. Similarly, comparisons of Figures $4 \mathrm{a}-4 \mathrm{c}$ with Figures $4 \mathrm{~g}-4 \mathrm{i}$, and Figures $4 \mathrm{~d}-4 \mathrm{f}$ with Figures $4 \mathrm{j}-41$ indicate that cracked flexural rigidity of components should be taken in the analysis. This figure also indicates that semirigid beam-column junction minimizes difference between FE model and experimental value of initial lateral stiffness. On the whole, Figure $4 \mathrm{k}$ gives the best 

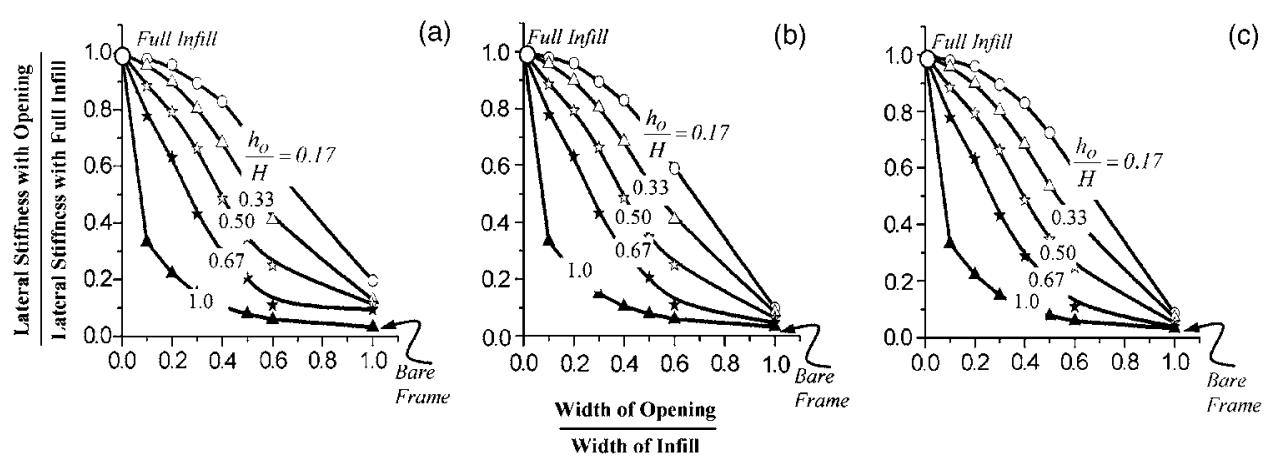

Figure 5. Effect of opening size on lateral stiffness of infilled frame determined by FE analysis: (a) single-story, (b) two-story, and (c) three-story.

match between FE model and experimental results; this model considers cracked flexural rigidity of components, semirigid beam-column junction and separation of frameinfill interface at non-loaded diagonal.

\section{PARAMETRIC STUDY USING CALIBRATED FE MODEL}

The initial lateral stiffness of single-bay single-story, single-bay two-story, and single-bay three-story RC infilled frames with varying sizes of central openings are determined using calibrated FE model. Cracked flexural rigidity of components, semirigid beam column junction and frame-infill separation are considered in the analysis. The RC beams and columns are discretized as frame elements and the infill as $250 \mathrm{~mm}$ $\times 250 \mathrm{~mm}$ plane stress elements (Figure 2). A lateral load is applied at the roof level in combination with gravity load.

Initial lateral stiffness determined by FE analysis of frames is shown in Figure 5. Width and height of opening is normalized with respect to width and height of infill, respectively, and the lateral stiffness of infilled frames is normalized with respect to that of the fully infilled frames. The following observations are made from the analysis:

(a) Presence of opening significantly reduces the initial lateral stiffness of infilled frames. As expected, the lateral stiffness decreases with increase of area of opening. When central opening occupies about $15 \%$ of the infill area, initial lateral stiffness is reduced by about $40 \%$.

(b) A sharp decrease in initial lateral stiffness is observed for the openings extended to full height or full width of the infill. This is because extension of opening to the full height or full width of infill divides infill panel into two sub-panels and the single diagonal strut cannot develop.

(c) In case of two similar rectangular frames with equal areas of openings, the frame having larger width of opening exhibits more initial lateral stiffness. This is because the possibility of formation of single diagonal strut is more in case of larger width of opening as the panels considered in the analysis are rectan- 

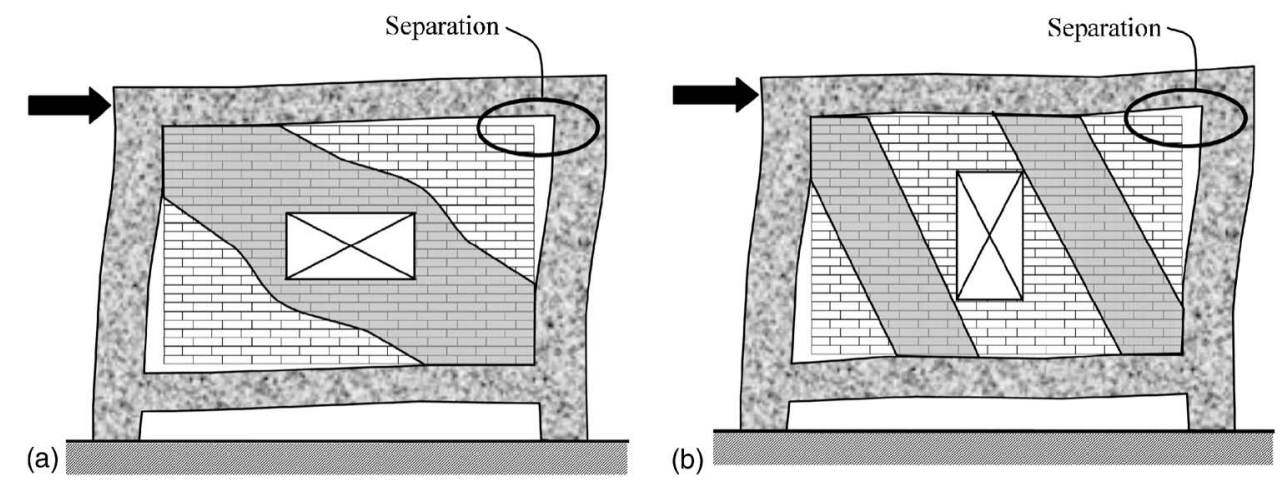

Figure 6. Formation of diagonal strut: (a) single diagonal strut, (b) multi-strut.

Table 2. Effect of dimensions of opening on initial lateral stiffness of infilled frame

\begin{tabular}{|c|c|c|c|c|}
\hline \multicolumn{2}{|c|}{ Width Smaller than Height } & \multicolumn{2}{|c|}{ Width Larger than Height } & \multirow[b]{2}{*}{$\begin{array}{l}\text { Difference } \\
(\%)\end{array}$} \\
\hline $\begin{array}{l}\text { Opening Size } \\
(\mathrm{mm} \times \mathrm{mm})\end{array}$ & $\begin{array}{l}\text { Lateral Stiffness } \\
(\mathrm{KN} / \mathrm{mm})\end{array}$ & $\begin{array}{l}\text { Opening Size } \\
(\mathrm{mm} \times \mathrm{mm})\end{array}$ & $\begin{array}{l}\text { Lateral Stiffness } \\
(\mathrm{KN} / \mathrm{mm})\end{array}$ & \\
\hline & & Single Story & & \\
\hline $500 \times 1000$ & 125 & $1000 \times 500$ & 120 & -4.2 \\
\hline $500 \times 1500$ & 114 & $1500 \times 500$ & 117 & 2.5 \\
\hline $500 \times 2000$ & 98 & $2000 \times 500$ & 105 & 5.8 \\
\hline $1000 \times 1500$ & 97 & $1500 \times 1000$ & 101 & 3.3 \\
\hline $1000 \times 2000$ & 75 & $2000 \times 1000$ & 85 & 8.3 \\
\hline \multirow[t]{2}{*}{$1500 \times 2000$} & 54 & $2000 \times 1500$ & 62 & 6.7 \\
\hline & & Two Story & & \\
\hline $500 \times 1000$ & 68 & $1000 \times 500$ & 70 & 1.7 \\
\hline $500 \times 1500$ & 62 & $1500 \times 500$ & 64 & 1.7 \\
\hline $500 \times 2000$ & 51 & $2000 \times 500$ & 58 & 5.8 \\
\hline $1000 \times 1500$ & 54 & $1500 \times 1000$ & 55 & 0.8 \\
\hline $1000 \times 2000$ & 41 & $2000 \times 1000$ & 47 & 5.0 \\
\hline \multirow{2}{*}{$1500 \times 2000$} & 29 & $2000 \times 1500$ & 32 & 2.5 \\
\hline & & Three story & & \\
\hline $500 \times 1000$ & 44 & $1000 \times 500$ & 44 & 0.0 \\
\hline $500 \times 1500$ & 40 & $1500 \times 500$ & 41 & 0.8 \\
\hline $500 \times 2000$ & 35 & $2000 \times 500$ & 38 & 2.5 \\
\hline $1000 \times 1500$ & 36 & $1500 \times 1000$ & 37 & 0.8 \\
\hline $1000 \times 2000$ & 29 & $2000 \times 1000$ & 31 & 1.7 \\
\hline $1500 \times 2000$ & 20 & $2000 \times 1500$ & 22 & 1.7 \\
\hline
\end{tabular}



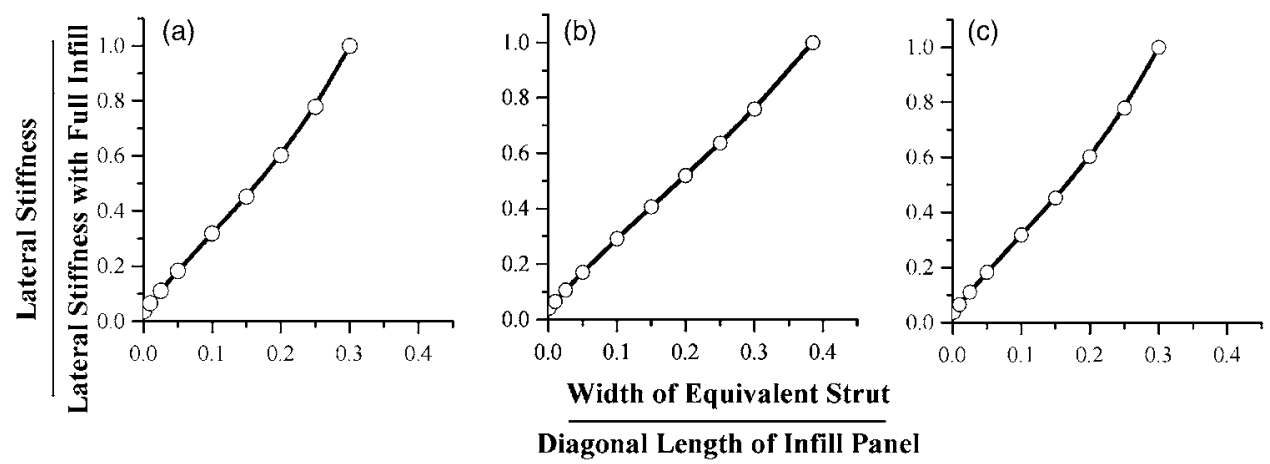

Figure 7. Effect of width of equivalent diagonal strut determined by single equivalent diagonal strut analysis on lateral stiffness: (a) single-story, (b) two-story, and (c) three-story.

gular $(5000 \mathrm{~mm} \times 3000 \mathrm{~mm})$ (Figure 6). As the height of opening increases the panel is divided into two sub-panels which increase the possibility of formation of multi-strut as shown in Figure 6.

(d) For the same area of opening if the dimensions of opening vary, the difference in initial stiffness is less than $10 \%$ (Table 2). Hence, except in extreme cases, area of opening (and not the height-to-width ratio of opening) governs the lateral stiffness of infilled frame. Therefore, the reduction factor proposed in this article does not depend upon the height to width ratio of the opening.

\section{SINGLE EQUIVALENT DIAGONAL STRUT (SEDS) ANALYSIS}

Initial lateral stiffness of the three identical infilled frames (namely single-story, twostory and three-story) is also obtained by SEDS analysis. In this analysis, infills are modelled as single equivalent diagonal struts and the widths of diagonal struts are taken as $0.001 d, 0.01 d, 0.025 d, 0.05 d, 0.1 d, 0.15 d, 0.2 d, 0.25 d, 0.3 d, 0.4 d$ and $0.5 d$, where $d$ in the diagonal length of infill. The strut is connected to the diagonal nodes at the beamcolumn joint so that it can take only axial force. The thickness of the struts is kept same as that of the infill. The beams and columns are modelled as frame elements. Semirigid end-offsets are considered to account for the finite size of beam-column junctions. Cracked flexural rigidity of components and modulus of elasticity of masonry $E_{m}=550 f_{m}$ are considered for the analysis.

The effect of strut-width on lateral stiffness of the infilled frames is shown in Figure 7. It is seen that the lateral stiffness of infilled frames increases almost linearly with increase in strut-width. 


\section{STRUT-WIDTH REDUCTION FACTOR}

The effect of opening on the lateral stiffness of the infilled frame can be represented by a diagonal strut of reduced width. This reduction in strut-width can be represented by a factor $\left(\rho_{w}\right)$, which is defined as ratio of reduced strut-width to strut-width corresponding to fully infilled frame, i.e.,

$$
\begin{aligned}
& \text { Strut }- \text { width reduction factor }\left(\rho_{w}\right) \\
& =\frac{\text { Strut }- \text { width of Infilled Frame with Opening }\left(w_{d o}\right)}{\text { Strut }- \text { width of Fully Infilled Frame }\left(w_{d s}\right)}
\end{aligned}
$$

For an infilled frame with a given size of opening, strut width required to obtain the lateral stiffness can be evaluated from Figure 8. From this figure, strut-widths are obtained for single-story, two-story, and three-story infilled frames with openings, considered in the present study. For example, in Figure 8, width of equivalent diagonal strut is about $0.15 d$ for $\frac{l_{0}}{L}=0.6$ and $\frac{h_{0}}{H}=0.33$, regardless of the number of stories.

Area of opening, $A_{o p}$, is normalized with respect to area of infill panel, $A_{\text {infill }}$, and the ratio is termed as opening area ratio, $\alpha_{c o}$, i.e.,

$$
\text { Opening-Area-Ratio }\left(\alpha_{c o}\right)=\frac{\text { Area of Opening }\left(A_{o p}\right)}{\text { Area of Infill }\left(A_{\text {infill }}\right)}
$$

Strut width reduction factors for various opening-area-ratios for all the frames are obtained and are shown in Figure 9. A sharp decrease of initial stiffness has been observed when the opening is extended up to full height or full width of the panel. Except such extreme cases, it is observed that the area of opening is important for initial lateral stiffness of infilled frame. Therefore, the cases in which the openings are extended up to the full height or full width of the panel $\left(\frac{h_{0}}{H}=1\right.$ or $\left.\frac{l_{0}}{L}=1\right)$ are excluded in regression analysis as they do not reflect the strut action adequately. Regression analyses of these data are performed and, linear, second-order polynomial, and third-order polynomial trend lines are shown in Figure 9. Also shown in this figure are the equations of the trend lines and the coefficient of correlation (R-value).

The linear-fit follows the data reasonably well with $R$ value of about 0.97 . The polynomials of higher order fit the data slightly better than linear-fit with $R$ value about 0.98 . However, considering the simplicity the following linear-fit equations adequately represent the data:

$$
\begin{gathered}
\rho_{w}=1-2.47 \alpha_{c o} \text { (one story) } \\
\rho_{w}=0.96-2.56 \alpha_{c o} \text { (two story) } \\
\rho_{w}=1.05-2.56 \alpha_{c o} \text { (three story) }
\end{gathered}
$$

These equations show that the strut-width reduction factor is not sensitive to the number of stories. Hence, data of all the three stories are plotted in a single figure and 


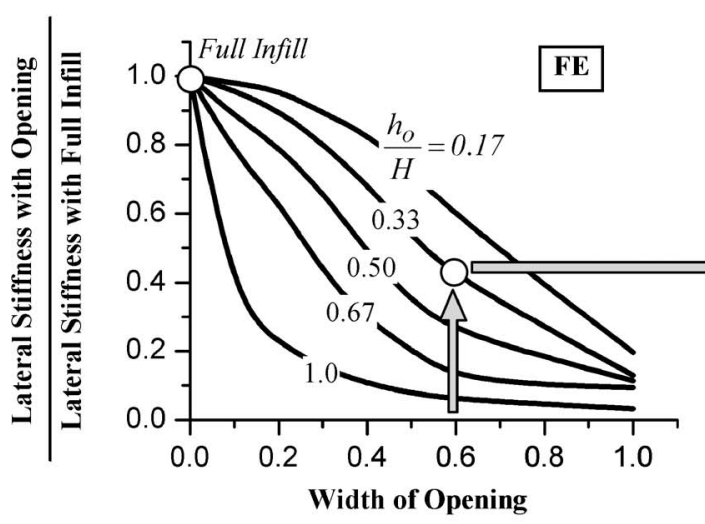

(a)

Width of Infill

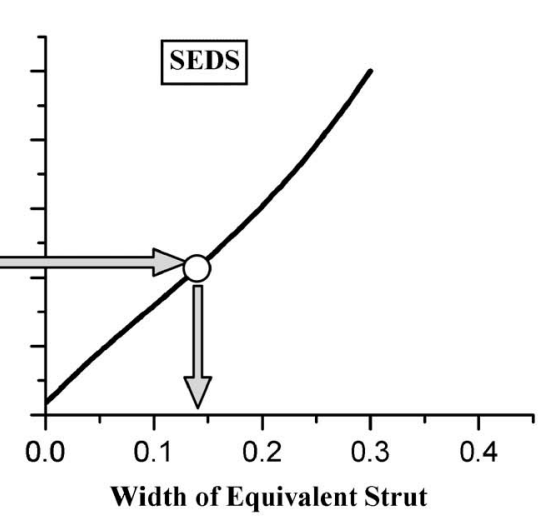

Diagonal Length of Infill Panel

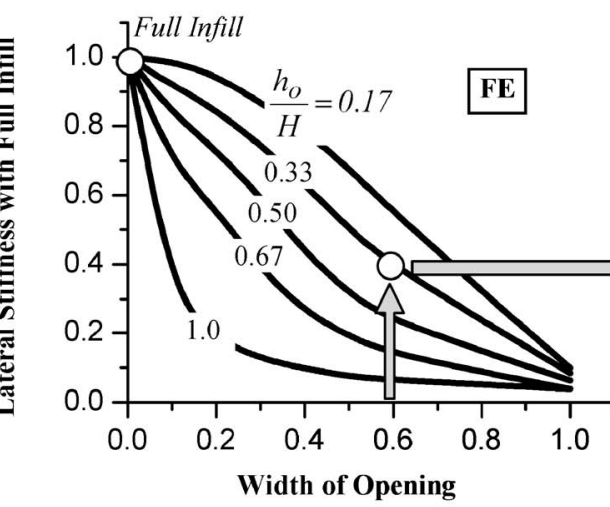

(b)

Width of Infill

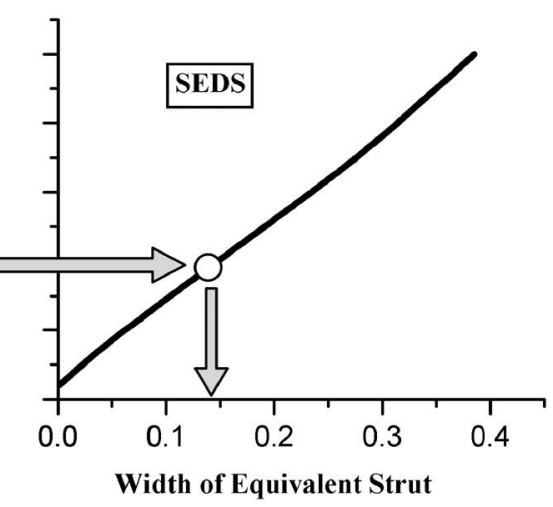

(c)

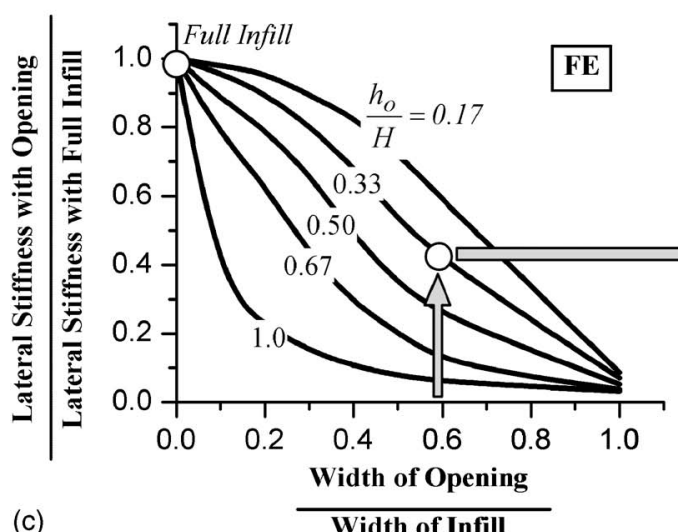

Width of Infill

Diagonal Length of Infill Panel

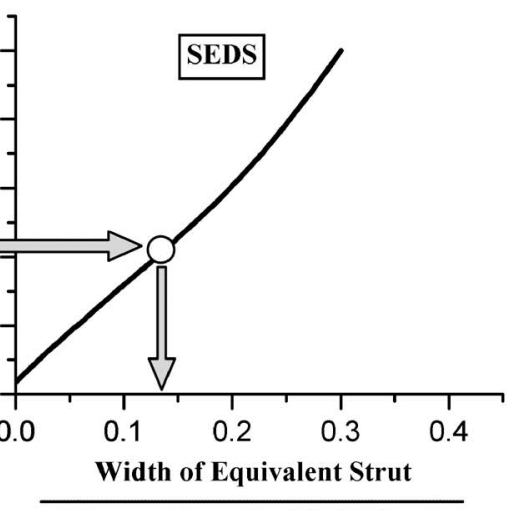

Diagonal Length of Infill Panel

Figure 8. Effect of opening size on equivalent diagonal strut: (a) single-story, (b) two-story, and (c) three-story. 

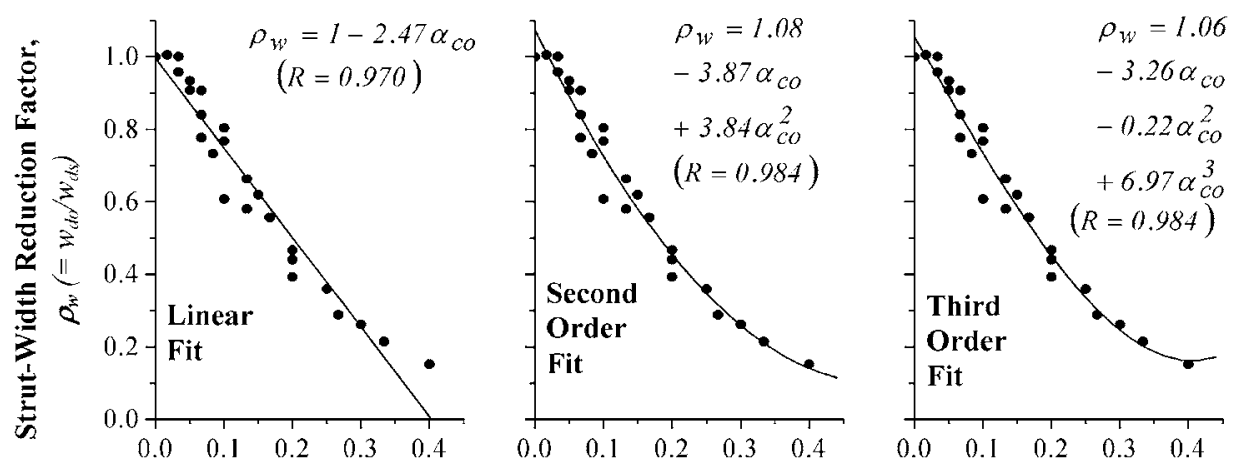

(a)

Opening-Area-Ratio, $\alpha_{c o}\left(=A_{o p} / A_{\text {infill }}\right)$
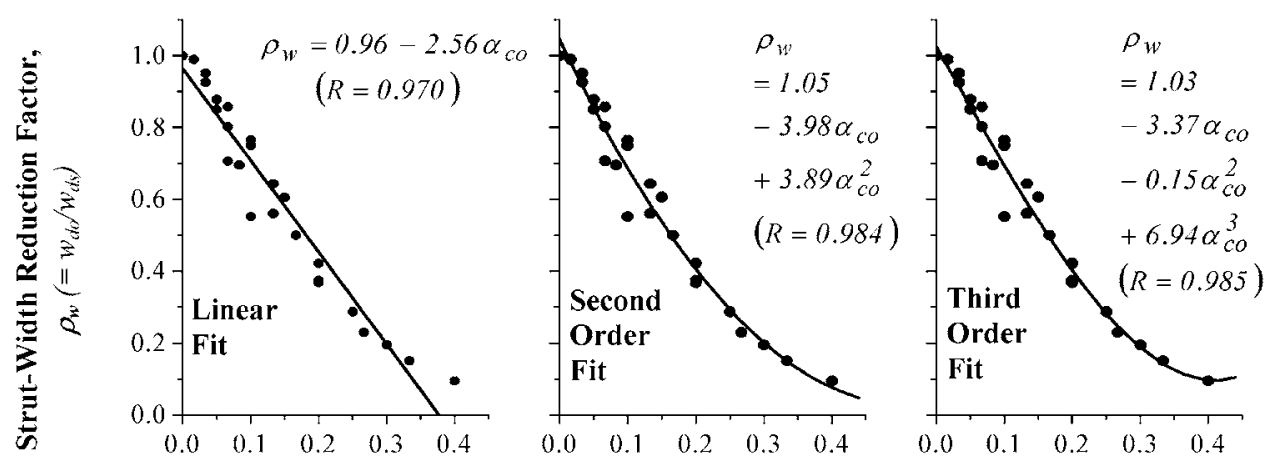

(b)

Opening-Area-Ratio, $\alpha_{c o}\left(=A_{o p} / A_{\text {infill }}\right)$

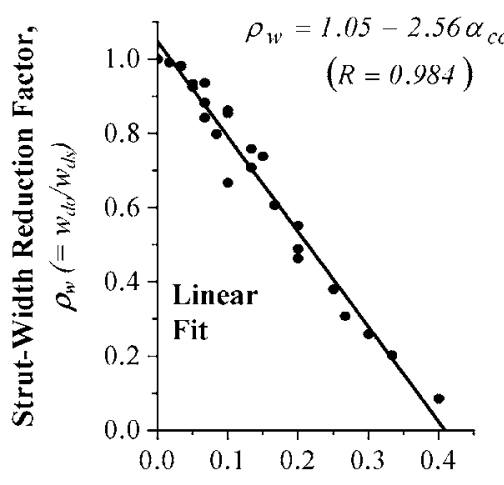

(c)
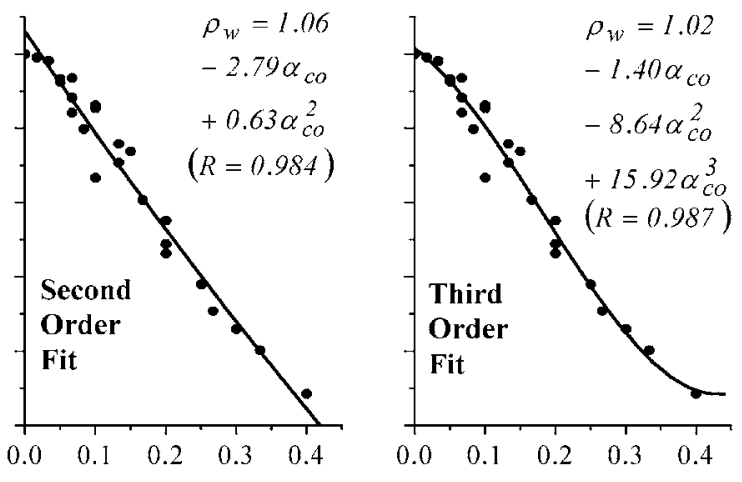

Opening-Area-Ratio, $\alpha_{c o}\left(=A_{O \rho} / A_{\text {infill }}\right)$

Figure 9. Effect of opening-area-ratio on strut-width reduction factor: best fit curves of analytical results (a) single-story, (b) two-story, and (c) three-story.

regression analysis is performed on the combined data. A linear-fit curve $\left(\rho_{w}=0.99\right.$ $-2.58 \alpha_{c o}$, with $R=0.965$ ) follows the trend of data reasonably well (Figure 10). Based on the above equations and linear fit curve, the reduction factor for the infilled frame with opening can be simplified as: 


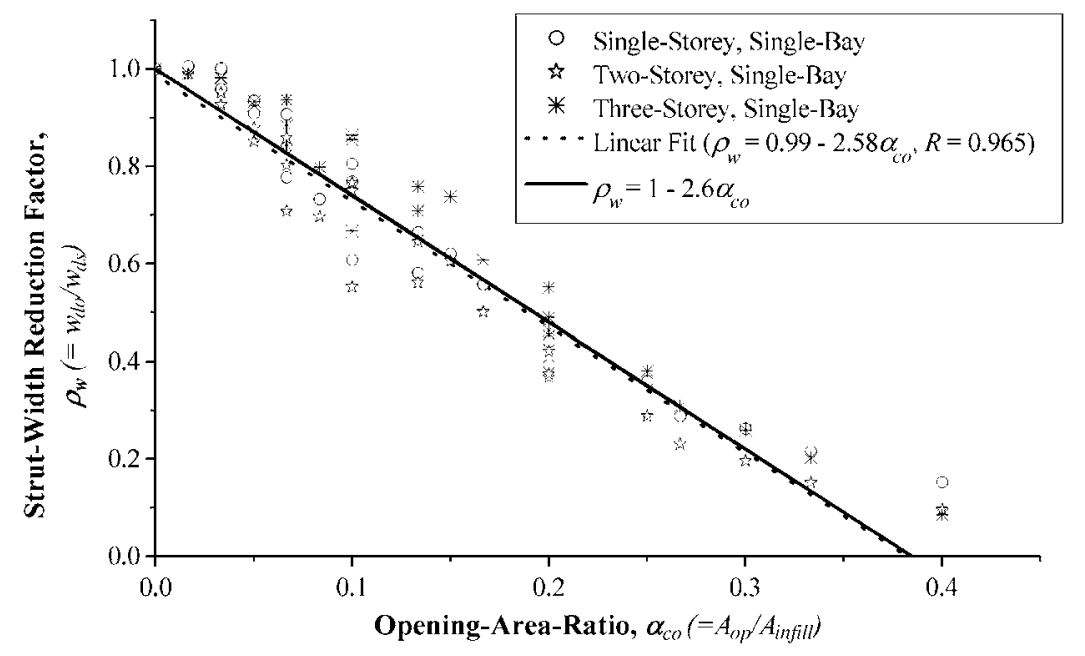

Figure 10. Linear trend line of all the merged data and comparison with the proposed equation of strut-width reduction factor.

$$
\rho_{w}=1-2.6 \alpha_{c o}
$$

regardless of the number of stories. The above expression for the reduction factor (i.e., $\rho_{w}=1-2.6 \alpha_{c o}$ ) is also plotted in Figure 10. The comparison between this curve and the linear fit curve shows that the proposed equation (Equation 8) is a good estimation of initial lateral stiffness of the infilled frame with a central opening.

Thus one may conclude that the stiffness contribution of infill may be neglected when opening area is greater that $40 \%$ of the area of infill. Similarly, presence of opening may be ignored if it is less than $5 \%$ of area of infill panel.

\section{WIDTH OF STRUT}

The reduction factor proposed above is with respect to analytical strut-width for fully infilled frame. In practice, one may use strut-width of solid infilled frames based on a number of equations available in the literature, each giving a different value of lateral stiffness. There has been a concern by some researchers (Meharbi et al. (1994), AlChaar (2002), and Al-Chaar et al. (2003a, 2003b)) that the single equivalent diagonal strut does not predict satisfactorily the lateral stiffness of infilled frame. It is therefore important to compare the width of diagonal strut of solid infilled frames obtained from several empirical relationships available in the literature with that obtained by the finite element analysis. The following relations have been considered:

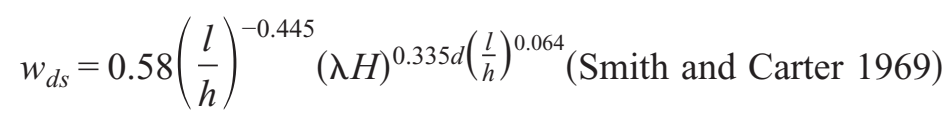


Table 3. Comparison of width of equivalent diagonal strut for infilled frame without opening

\begin{tabular}{|c|c|c|c|c|c|c|c|c|c|c|c|}
\hline \multirow[b]{3}{*}{$\begin{array}{l}\text { Fully Infilled } \\
\text { Frames }\end{array}$} & \multicolumn{11}{|c|}{ Width of Strut of Solid Infill } \\
\hline & FEM & \multicolumn{2}{|c|}{$\begin{array}{c}\text { Smith and } \\
\text { Carter, } 1969 \\
\end{array}$} & \multicolumn{2}{|c|}{$\begin{array}{c}\text { Mainstone, } \\
1971\end{array}$} & \multicolumn{2}{|c|}{$\begin{array}{c}\text { Paulay and } \\
\text { Priestley, } 1992\end{array}$} & \multicolumn{2}{|c|}{$\begin{array}{c}\text { Liauw and } \\
\text { Kwan, } 1984\end{array}$} & \multicolumn{2}{|c|}{$\begin{array}{c}\text { Holmes, } \\
1961 \\
\end{array}$} \\
\hline & $\mathrm{mm}$ & $\mathrm{mm}$ & $\begin{array}{c}\text { Error } \\
(\%)\end{array}$ & $\mathrm{mm}$ & $\begin{array}{c}\text { Error } \\
(\%)\end{array}$ & $\mathrm{mm}$ & $\begin{array}{l}\text { Error } \\
(\%)\end{array}$ & $\mathrm{mm}$ & $\begin{array}{c}\text { Error } \\
(\%)\end{array}$ & $\mathrm{mm}$ & $\begin{array}{l}\text { Error } \\
(\%)\end{array}$ \\
\hline 1-Story & 1577 & 4059 & -157.4 & 635 & 59.7 & 1458 & 7.6 & 1352 & 14.3 & 1944 & -23.2 \\
\hline 2-Story & 1785 & & -127.4 & & 64.4 & & 18.3 & & 24.3 & & -8.9 \\
\hline 3-Story & 2245 & & -80.8 & & 71.7 & & 35.1 & & 39.8 & & 13.4 \\
\hline
\end{tabular}

$$
\begin{gathered}
w_{d s}=0.175(\lambda H)^{-0.4} d \text { (Mainstone 1971) } \\
w_{d s}=\frac{d}{4}(\text { Paulay and Priestley 1992) } \\
w_{d s}=\frac{(0.95 h \cos \theta)}{\sqrt{\lambda H}}(\text { Liauw and Kwan 1984) } \\
w_{d s}=\frac{d}{3}(\text { Holmes 1961) }
\end{gathered}
$$

In Table 3 the widths of struts for single-story, two-story, and three-story solid infill, calculated by the Equations 9-13, are compared with the widths of struts determined by FE method. The difference in width of strut from FE analysis and that using Equation 9 (Smith and Carter 1969) is up to $150 \%$. Strut width proposed by Mainstone (1971) substantially underestimates the lateral stiffness of infilled frames (the strut width proposed by Mainstone is $60 \%$ to $70 \%$ smaller than that found from FE analysis) which supports the conclusion of Meharbi et al. (1994, 2003). Therefore, the proposed reduction factor cannot be applied to widths of struts proposed by Smith and Carter (1969), and Mainstone (1971). However, results from Equations 11-13 (Paulay and Priestley 1992, Liauw and Kwan 1984, and Holmes 1961) compare well with the strut widths from FE analysis. Hence, only these three proposals are considered for further discussion.

New strut-width reduction factor values are calculated wherein the strut-width of solid infill $\left(w_{d s}\right)$ is based on Equations 11, 12 or 13. Two linear-fits are considered, one is the best fit and the other a constrained fit with the $\rho_{w}$-intercept forced to be unity (Figure 11). Poor correlations are obtained for strut-width reduction factor values from Equations 11 (Paulay and Priestley 1992) and 12 (Liauw and Kwan 1984). On the other hand, the width of strut using Equation 13 (Holmes 1961) provides the best results for the proposed strut-width reduction factor for infilled frames with openings. The two equations for unconstrained fit $\left(\rho_{w}=0.96-2.44 \alpha_{c o}, R=0.928\right)$ and constrained fit $\left(\rho_{w}=1-2.62 \alpha_{c o}, R=0.924\right)$ match very well (Figure 11). Furthermore, the constrained fit curve is very close to the proposed strut-width reduction factor (i.e., $\rho_{w}=1-2.6 \alpha_{c o}$ ). 


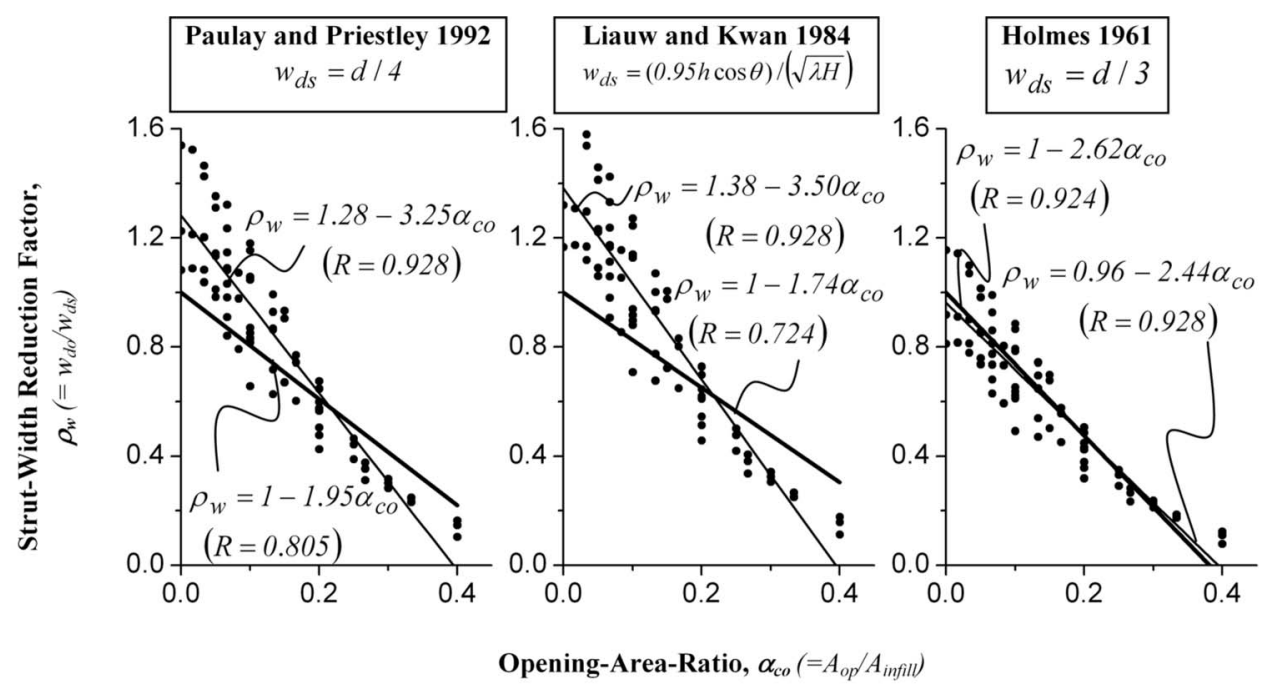

Figure 11. Strut-width reduction factor based on available strut-width for solid infill.

Therefore, the strut-width for solid infill as per Equation 13 (Holmes 1961) can be taken as the basis to apply the proposed strut-width reduction factor due to presence of opening.

\section{VERIFICATION OF THE PROPOSED REDUCTION FACTOR}

In the parametric study, all the parameters except the number of stories and the size of openings are kept constant for different models. Based on this, a reduction factor for infilled frames with openings is proposed. To demonstrate the applicability of the proposed reduction factor, some of the parameters of the single-bay single-story model are changed one at a time while all others are kept constant. In addition, results of experimental specimens available in the literature are considered to verify the proposed strutwidth reduction factor. Moreover, the proposed strut-width reduction factor is compared with that proposed by Durrani and Luo (1994), and by Al-Chaar (2002).

The effects of the sizes of beam and column, compressive strength of concrete, thickness and area of infill panel on strut-width reduction factor are shown in Table 4. It is seen that a $37.5 \%$ reduction in size of beam results in $8 \%$ error in the strut-width reduction factor. Similarly, $70 \%$ reduction in size of column leads to $8 \%$ error in reduction factor. A $7 \%$ error in reduction factor was observed due to a $20 \%$ increase in the compressive strength of concrete. Table 4 also displays that reduction factor is weakly dependent on thickness and area of infill panel. All these strut-width reduction factors are also plotted in Figure 12 along with the proposed strut-width reduction factor as per Equation 8, which shows that there is not much variation in the reduction factor in relation to the changes made in the parameters.

The proposed reduction factor is further verified with three experimental specimens 
Table 4. Effect of change of parameters on strut-width reduction factor

\begin{tabular}{|c|c|c|c|c|c|}
\hline \multirow[b]{2}{*}{ Parameters } & \multirow[b]{2}{*}{ In Parametric Study } & \multirow[b]{2}{*}{ In Verification } & \multicolumn{3}{|c|}{$\begin{array}{l}\text { Error in Reduction Factor }(\%) \\
\text { for Different Opening Size }\left(\mathrm{mm}^{2}\right)\end{array}$} \\
\hline & & & $1000 \times 1000$ & $1500 \times 1500$ & $2500 \times 1500$ \\
\hline $\begin{array}{l}\text { Size of Beam } \\
\left(\mathrm{mm}^{2}\right)\end{array}$ & $250 \times 400$ & $250 \times 250$ & 7.7 & 8.3 & 0.0 \\
\hline $\begin{array}{l}\text { Size of Column } \\
\left(\mathrm{mm}^{2}\right)\end{array}$ & $400 \times 400$ & $250 \times 250$ & 8.1 & 3.2 & 1.2 \\
\hline$f_{c k}(\mathrm{MPa})$ & 25 & 30 & 7.0 & 4.7 & 6.9 \\
\hline $\begin{array}{l}\text { Thickness of Infill } \\
(\mathrm{mm})\end{array}$ & 225 & 112.5 & 12.0 & 1.7 & 0.0 \\
\hline $\begin{array}{l}\text { Area of Infill Panel } \\
\left(\mathrm{mm}^{2}\right)\end{array}$ & $3000 \times 5000$ & $4000 \times 5000$ & 4.8 & 9.0 & 2.0 \\
\hline
\end{tabular}

published in literature. These include single-bay single-story specimens with a window opening of Raj (2000), Choubey and Sinha (1994), and Combescure and Pegon (2000). The first two specimens were also used earlier for calibration of the finite element model (Table 1). Single equivalent diagonal strut analysis of these three specimens are performed in SAP 2000 where the infills are modelled as diagonal strut, and the width of struts is varied to find the strut-width which gives stiffness same as the experimental initial stiffness value of these specimens. The corresponding strut-width reduction factor for the three specimens are also plotted in Figure 12 which shows a good match with proposed strut width reduction factor.

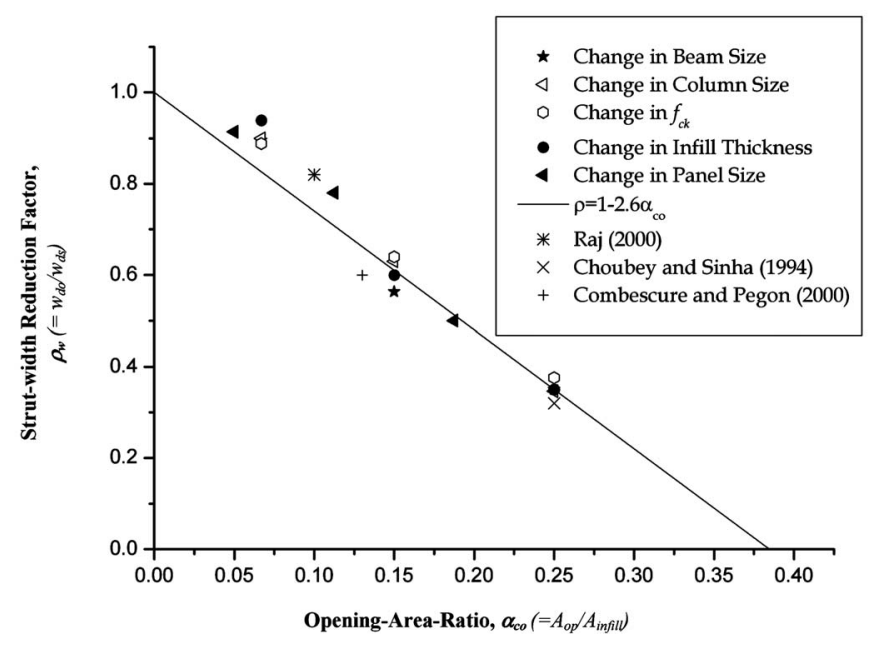

Figure 12. Verification of the proposed strut-width reduction factor. 


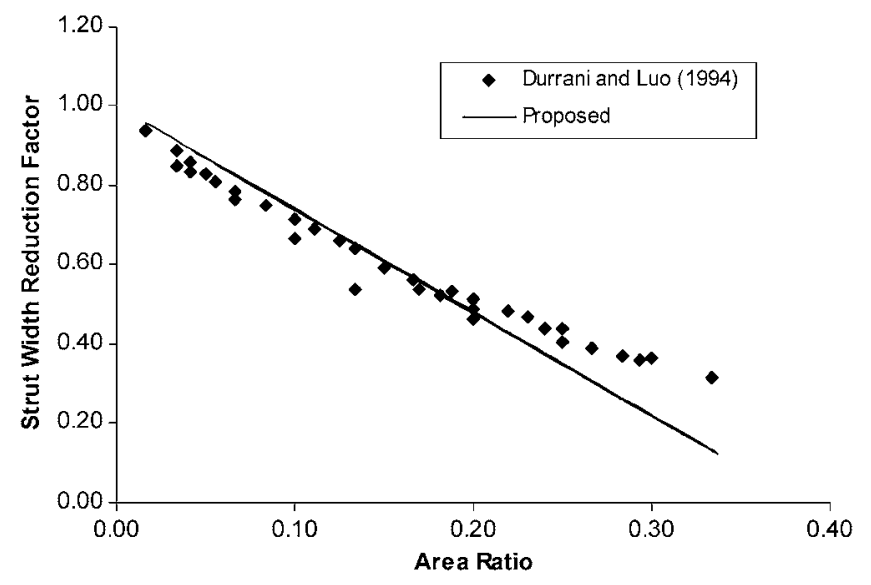

Figure 13. Comparison of proposed strut width reduction factor with that proposed by Durrani and Luo (1994).

The proposed strut width reduction factor is also compared with that proposed by Durrani and Luo (1994). For this comparison, infilled frames of aspect ratios 0.6 to 1.3 and central opening of aspect ratios 0.5 to 4.0 are considered. Figure 13 shows that the proposed reduction factor matches well with that proposed by Durrani and Luo (1994) up to area ratio 0.25 and beyond that Durrani and Luo (1994) give substantially higher value of reduction factor. The expression developed in the present study is far simpler than that proposed by Durrani and Luo (1994) and is very easy to implement in the design office.

The proposed reduction factor is also compared indirectly with that proposed by AlChaar (2002). The reduction factor proposed by Al-Chaar estimates the in-plane capacity (strength) of the infilled frame satisfactorily. However, it does not predict the initial lateral stiffness with sufficient accuracy. The initial lateral stiffness of infilled frame obtained from Al-Chaar's experiment is almost three times larger (for aspect ratio of panel between 0.67 and 1.5) than that estimated from the bilinear pushover curve of infilled frame obtained by using strut-width proposed by Al-Chaar (2002). Moreover, reduction factor for strength to account for openings proposed by Al-Chaar should be applied for eccentric single equivalent strut where strut element is connected to the columns rather than to the beam-column joints. Therefore, it is not possible to directly compare the strut width reduction factor. Instead, lateral stiffness reduction due to presence of openings obtained by using strut width proposed by Al-Chaar (2002) and that proposed in the present study are compared. For this purpose, specimen of Choubey and Sinha (1994) with varying opening size is considered. Figure 14 shows that Al-Chaar's reduction factor somewhat overestimates the stiffness reduction. This difference becomes quite significant beyond the area ratio of 0.25 . 


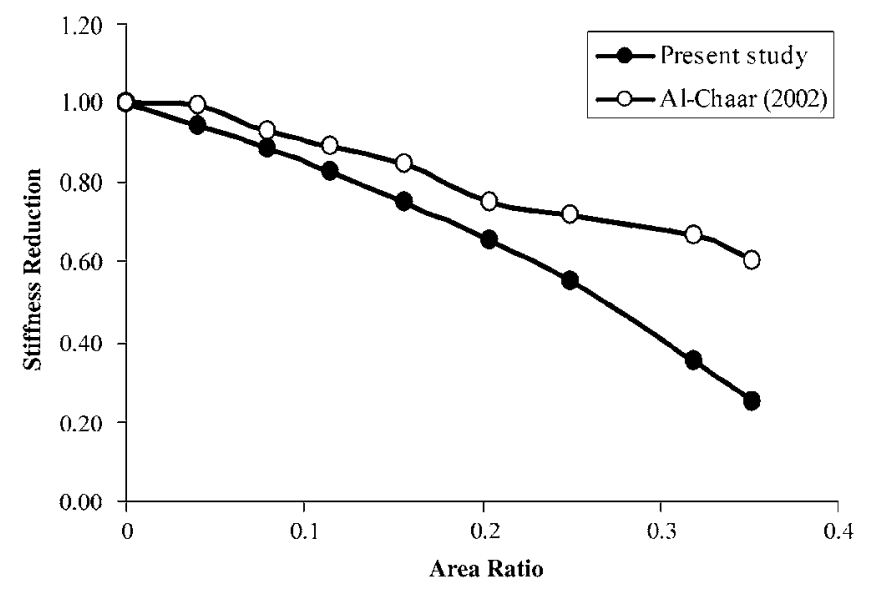

Figure 14. Comparison of stiffness reduction obtained by using proposed strut width reduction factor and that proposed by Al-Chaar (2002).

\section{SUMMARY AND CONCLUSIONS}

In many countries, multistory buildings are commonly built with reinforced concrete frame and masonry infill walls. Such buildings are usually designed assuming the infill walls to be nonstructural and ignoring their strength and stiffness. However, the recent earthquakes illustrate the significant structural contribution of the infill wall implying that infill wall should be taken into consideration in the design process. Some codes contain provisions for modeling solid infill walls using the diagonal strut method. Generally, infilled frames with openings have not been adequately covered in the codes.

In the present study, a reduction factor is proposed for effective width of diagonal strut over that of the solid infilled frame to calculate its initial stiffness when a central window opening is present. Seven specimens of infilled frame for which details of the specimens and experimental results are available in the published literature are considered. These include single-bay single-story to single-bay multi-story bare frames, infilled frames without openings, and infilled frames with central openings. These specimens are analyzed by Finite Element (FE) method using the software SAP 2000 Version 8 (CSI 2000a, 2000b). The present study is based on initial lateral stiffness corresponding to $10 \%$ of the lateral strength of the infilled frames. Based on the comparison between initial lateral stiffness using FE method and from experimental initial lateral stiffness it is found that best match with experimental results are obtained when (a) separation between the frame and the infill at the non-loaded diagonal is included, (b) end-offsets of beam-column joints in RC frames is assumed to be semirigid wherein quarter columndepth along beam from center line of column and quarter beam-depth along column from center line of beam are considered rigid, (c) the FE model is based on cracked flexural rigidity of beams and columns where the flexural rigidity of beam and column in tension is taken as $0.5 E_{c} I_{g}$ and that of column in compression is taken as $0.7 E_{c} I_{g}$ 
(ATC-40 1996), (d) modulus of elasticity of concrete $\left(E_{c}\right)$ is assumed as $E_{c}=5000 \sqrt{f_{c k}}$, where $f_{c k}$ is the characteristic compressive strength $(\mathrm{MPa})$ of concrete cube at 28 days, and (e) modulus of elasticity of masonry is taken as $E_{m}=550 f_{m}$ (Drysdale et al. 1993), where $f_{m}$ is the compressive strength of masonry prism in MPa. Based on such a FE model, parametric study is performed for single-bay single-story, single-bay two-story and single-bay three-story infilled frames with different opening sizes.

It was proposed that in the single diagonal strut model of fully infilled frame, the width of the strut can be taken as one third of the diagonal length of the infill as proposed by Holmes (1961). The presence of central opening can be considered by reducing the effective width through a reduction factor, $\rho_{w}=1-2.6 \alpha_{c o}$, where $\alpha_{c o}=$ ratio of the area of opening to the area of the infill. The applicability of this proposed reduction factor is verified by varying some of the parameters that are kept constant during the parametric study and with three experimental specimens; these show good agreement.

It can also be concluded that the effect of opening on the initial lateral stiffness of infilled frames should be neglected if the area of opening is less than $5 \%$ of the area of the infill panel, and the strut-width reduction factor should be set to one, i.e., the frame is to be analyzed as a solid infilled frame. The effect of infill on the initial lateral stiffness of infilled frame may be ignored if the area of opening exceeds $40 \%$ of the area of the infill panel, and the strut-width reduction factor should be set to zero, i.e., the frame is to be analyzed as a bare frame. The proposed reduction factor is applicable for infilled frame with normal openings. Extreme cases where openings are extended to full height or full width of the infilled frame cannot be covered by the proposed reduction factor.

The present study is limited to infilled frames with central openings. Future work should be performed to obtain the effect of location of opening in the infilled frame. The effect of lintel bands or different types of stiffeners on the reduction factor should also be investigated.

\section{REFERENCES}

American Concrete Institute (ACI), 2005. ACI 318-05: Building Code Requirements for Structural Concrete, ACI Committee 318, Farmington Hills, Michigan, 430 pp.

Al-Chaar, G., 2002. Evaluating strength and stiffness of unreinforced masonry structures, ERDC/CERL TR-02-1, US Army Corps of Engineers, Construction Engineering Research Laboratories.

Al-Chaar, G., Issa., M., and Sweeney, S., 2002. Behavior of masonry-infilled nonductile reinforced concrete frames, J. Struct. Eng., ASCE 128, 1055-1063.

Al-Chaar, G., Lamb, G. E., and Abrams, D. P., 2003a. Effects of openings on structural performance of unreinforced masonry infilled frames, Proceedings, Ninth North American Masonry Conference, Clemson University, Canada.

Al-Chaar, G., Lamb, G. E., and Issa, M. A., 2003b. Effects of openings on structural performance of unreinforced masonry infilled frames, in Large Scale Structural Testing, Issa, M. A. and Mo, Y. L., eds., American Concrete Institute, SP-211.

Applied Technology Council (ATC), 1996. Seismic Evaluation and Retrofit of Concrete Buildings, volumes 1 and 2, Report No. ATC-40, Redwood City, CA. 
Buonopane, S. G., and White, R. N., 1999. Pseudodynamic testing of masonry infilled reinforced concrete frame, J. Struct. Eng., ASCE 125, 578-589.

Bureau of Indian Standards (BIS), 2000. Indian Standard Code of Practice for Plane and Reinforced Concrete, IS:456-2000, 4th revision, Bureau of Indian Standards, New Delhi.

Choubey, U. B., and Sinha, S. N., 1994. Cyclic response of infilled frames, J. Struct. Eng., SERC Chennai 21, 203-211.

Combescure, D., and Pegon, P., 2000. Application of the local to global approach to the study of infilled frame structures under seismic loading, Proceedings, Twelfth World Conference on Earthquake Engineering, CD ROM Paper No. 0505, Auckland, New Zealand.

CSI, 2000a. Integrated Software for Structural Analysis and Design: Analysis Reference Manual, Computer and Structures, Inc., Berkeley, CA.

— 2000b. Integrated Software for Structural Analysis and Design: Getting Started, Basic Analysis Reference and Introductory Tutorial, Computer and Structures, Inc., Berkeley, CA.

Dawe, J. L., and Seah, C. K., 1989. Behavior of masonry infilled steel frames, Can. J. Civ. Eng. 16, 865-876.

Drysdale, R. G., Hamid, A. A., and Baker, R. L., 1993. Masonry Structures: Behavior and Design, Prentice Hall Inc., Upper Saddle River, NJ.

Durrani, A. J., and Luo, Y. H., 1994. Seismic Retrofit of Flat-Slab Buildings with Masonry Infills, Proceedings from the NCEER Workshop on Seismic Response of Masonry Infills, Technical Report NCEER-94-0004, D. P. Abrams (editor), pp. 1-8.

Federal Emergency Management Agency (FEMA), 1997. NEHRP Guidelines for the Seismic Rehabilitation of Buildings, FEMA-273, 1997, Washington, DC.

Holmes, M., 1961. Steel frames with brickwork and concrete infilling, Proceedings of the Institution of Civil Engineers 19, 473-478 (eISSN 1753-7789).

Jagadish, R. H., Achyutha, H., and Rao, P. S., 1992. Behavior of reinforced concrete brick masonry infilled frames with stiffened window opening, Proceedings of the 4th International Seminar on Structural Masonry for Developing Countries, Madras, India, pp. 143-149.

Kaushik, H. B., Rai, D. C., and Jain, S. K., 2006. Code approaches to seismic design of masonry-infilled reinforced concrete frames: A state-of-the-art review, Earthquake Spectra 22, 961-983.

Kodur, V. K. R., Erik, M. A., and Quenneville, J. H. P., 1998. Seismic analysis of infilled frames, J. Struct. Eng., SERC Chennai 25, 95-102.

Liauw, T. C., 1972. An approximate method of analysis for infilled frames with or without opening, Build. Sci. 7, 233-238.

,- 1979 . Tests on multi-story infilled frames subject to dynamic lateral loading, ACI J. 76, $551-563$.

Liauw, T. C., and Kwan, K. H., 1984. Nonlinear behavior of non-integral infilled frames, Comput. Struct. 18, 551-560.

Mainstone, R. J., 1971. On the stiffness and strengths of infilled frames, Proceedings, Institution of Civil Engineers, Supplement IV, 57-90.

Mallick, D. V., and Garg, R. P., 1971. Effect of openings on the lateral stiffness of infilled frames, Proceedings of the Institution of Civil Engineers 49, 193-209.

Meharbi, A. B., and Shing, P. B., 2003. Seismic analysis of masonry infilled reinforced concrete frames, Masonry Soc. J. 21, 81-94. 
Meharbi, A. B., Shing, P. B., Schuller, M. P., and Noland, J. L., 1994. Performance of MasonryInfilled R/C Frames under In-Plane Lateral Loads, Report CU/SR-94/6. UC Colorado, CO.

Mondal, G., 2003. Lateral Stiffness of Unreinforced Brick Infilled RC Frame with Central Opening, M.Tech thesis, Indian Institute of Technology Kanpur, India.

Paulay, T., and Priestley, M. J. N., 1992. Seismic Design of Reinforced Concrete and Masonry Buildings, John Wiley \& Sons, Inc., New York, NY.

Pillai, E. B. P., 1995. Influence of Brick Infill on Multi-Story Multi-Bay R.C. Frames, Ph.D. thesis, Coimbatore Institute of Technology, India.

Polyakov, S. V., 1956. Masonry in Framed Buildings (An investigation into the strength and stiffness of masonry infilling). Gosudarstvennoe izdatel'stvo Literatury po stroitel'stvu i arkhitekture, Moscow. (English translation by G. L. Cairns, National Lending Library for Science and Technology, Boston, Yorkshire, England, 1963).

Raj, G. B. P., 2000. Experimental Investigation of R.C. Frames with Brick Masonry Infill Walls Having Central Opening Subjected to Cyclic Displacement Loading, M.Tech. thesis, Indian Institute of Technology Kanpur, India.

Smith, B. S., and Carter, C., 1969. A method of analysis for infilled frames, Proceedings of the Institute of Civil Engineers 44, Paper No. 7218, 31-48.

Thiruvengadam, V., 1985. On the natural frequencies of infilled frames, Earthquake Eng. Struct. Dyn. 13, 401-419.

(Received 1 August 2006; accepted 23 December 2007) 